\title{
Os sem-voto do Legislativo brasileiro: quem são os Senadores Suplentes e quais os seus impactos sobre o processo legislativo
}

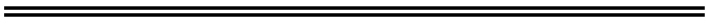 \\ Pedro Neiva \\ Centro Brasileiro de Análise e Planejamento \\ Mauricio Izumi \\ Centro Brasileiro de Análise e Planejamento \\ Mestrando em Ciência Política - Universidade de São Paulo
}

\begin{abstract}
Resumo: Este artigo tem dois objetivos principais. O primeiro é elaborar um perfil dos suplentes de Senadores no Brasil em comparação com os Senadores titulares. O segundo objetivo é avaliar a sua atuação política, no intuito de identificar se exercem algum impacto sobre o funcionamento do Senado e sobre a sua relação com o Poder Executivo. Sugerimos que o fato de os suplentes não serem eleitos contribui para que eles sejam designados para tarefas "espinhosas" que poderiam gerar custos políticos para os Senadores titulares. Verificamos também que eles oferecem um apoio ligeiramente maior ao Poder Executivo, especialmente nas coalizões que contam com uma participação maior dos partidos de direita.
\end{abstract}

Palavras-chave: Legislativo; Senado; suplentes; perfil; elites

\begin{abstract}
This article has two main objectives. The first one is to create a profile of Senators' substitutes, compared to the elected Senators. The second objective is to investigate the substitutes' political performance, with the intent of evaluating the impact of their actions on both the functioning of the Senate and their relationship to the Executive Power. We suggest that, because they are not directly elected, they are selected to work on difficult tasks, especially those that could bring negative political effects to the Senators, which depend on the electorate's vote. We also found that the substitutes give a bit more support to the Presidency, particularly observed in right wing parties coalitions.
\end{abstract}

Keywords: Legislative; Senate; substitutes; Senator profiles; elites

OPINIÃO PÚBLICA, Campinas, vol. 18, no 1, Junho, 2012, p. 1-21 


\section{Introdução}

Neste artigo, fazemos um levantamento dos suplentes de senadores no Brasil, procurando identificar quem são eles, quais suas ocupações predominantes, como se distribuem pelos partidos, como são escolhidos e os cargos que costumam ocupar antes do mandato. Além disso, buscamos verificar quais os impactos que têm sobre o funcionamento do Senado, especialmente na sua relação com o Poder Executivo. O tema tem ganhado espaço na imprensa brasileira, especialmente depois dos escândalos que assolaram a instituição nos últimos anos. No entanto, ainda não mereceu um tratamento aprofundado por parte da Ciência Política, a exemplo do que ainda acontece com vários outros aspectos relacionados à nossa Câmara Alta.

Em um discurso bem humorado em março de 2010, o presidente Lula fez o comentário de que "o Senado é melhor do que o céu, já que para ir para o céu é preciso morrer; para o Senado, vai-se vivo". Em grande parte, o presidente tem razão. O cargo de senador é um dos mais confortáveis e um dos mais prestigiados no país. É o único que garante um mandato eletivo durante oito anos, sem impedir que o seu ocupante se candidate a outro cargo a cada dois anos. O senador tem um dos maiores salários dos órgãos públicos e diversas outras vantagens, tais como: verba para manutenção do gabinete e para transporte aéreo, cota postal e para telefones, auxílio moradia, carro oficial com combustível e motorista, ressarcimento de despesas médicas e verba que pode ser usada para fretamento de aeronaves, divulgação do mandato, assinatura de publicações, contratação de serviços de segurança. Segundo o portal na internet "Congresso em Foco" (2011), cada senador custa aos cofres públicos aproximadamente $\mathrm{R} \$ 150$ mil por mês, contra o custo de $\mathrm{R} \$ 115$ mil de um deputado federal.

Além disso, os senadores brasileiros contam com grande visibilidade política, ao fazerem parte de uma das câmaras altas mais poderosas do mundo (NEIVA, 2006). Não é à toa que por ela passaram muitas das maiores lideranças políticas da nossa história antiga e recente: nada menos do que 21 dos 27 presidentes eleitos na fase republicana já foram senadores, antes ou depois do mandato (NEIVA \& SOARES, 2010). Com a eleição de dois terços do Senado em 2010, calculamos que, em sua composição, a casa terá 37\% de ex-governadores. Números semelhantes foram encontrados por Miguel (2003) para o período 1982-1988: segundo o autor, 31,4\% dos senadores já haviam sido governadores.

No entanto, a despeito de todos os benefícios e do prestígio do cargo, nem sempre é necessário respaldo político para chegar a esse "paraíso". Pode-se chegar lá também financiando a campanha de um senador, por meio de um parente que se eleja para o cargo ou tendo alguma sorte na vida. É o caso da maioria dos senadores suplentes, que tomaram posse no lugar dos titulares.

A situação é preocupante por dois motivos principais. Em primeiro lugar, porque a sua frequência não é tão desprezível: estima-se que os suplentes responderam por mais de $16 \%$ dos votos dados no plenário do Senado no período posterior à Constituição de 1988. Em alguns momentos, a sua participação ficou próxima à quarta parte da Casa. Ela torna-se mais relevante nas matérias mais conflituosas, em que os votos dos suplentes podem ser decisivos.

Uma segunda preocupação deve-se ao fato de estarmos tratando dos únicos "representantes" do povo que exercem o poder sem terem obtido um único voto. Nem por isso são impedidos de participar das discussões e das decisões mais complexas e controversas, realizadas no âmbito do 
NEIVA, P.; IZUMI, M. Os sem-voto do legislativo brasileiro: quem são os Senadores...

Congresso Nacional. Conforme salientam autores diversos, a eleição é uma condição absolutamente necessária para a existência da democracia, ainda que não seja uma condição suficiente. É o caso de Schumpeter, segundo o qual "a democracia envolve um arranjo institucional, que permite chegar a decisões políticas pelas quais os indivíduos adquirem o poder de decidir mediante uma luta competitiva pelo voto popular." (SCHUMPETER, 1984, p. 250). De acordo com Di Palma, ela "tem como premissa [...] o sufrágio livre e isento em um contexto de liberdades civis, partidos competitivos, opção entre candidaturas, e instituições políticas que regulam e garantem os papéis do governo e da oposição" (DI PALMA, 1990, p.16). De acordo com O’Donnell, “em um regime democrático, as eleições são competitivas, livres, igualitárias, decisivas e includentes. Quando institucionalizadas, são o seu componente principal, já que se tratam do único meio de acesso às principais posições de governo." (O’DONNELL, 1999, p.587). Segundo Manin (1995), a condição de governante não pode ser obtida como uma dádiva divina, a partir da riqueza, do saber ou de qualquer outra qualidade intrínseca de certos indivíduos; ela é conquistada, unicamente, a partir da vontade e do consentimento daqueles que serão governados (todos os destaques são nossos).

No entanto, a existência da democracia não depende apenas de que os representantes sejam escolhidos por meio de eleições livres e isentas. Ela envolve também a capacidade de os eleitores influenciarem suas ações durante o mandato. E o instrumento principal para isso é a possibilidade que eles têm de negar o seu voto nas eleições seguintes. Assim, é necessário que elas sejam também frequentes, em intervalos regulares e periódicos (DAHL, 1989; MANIN, 1995; PRZEWORSKI, STOKES \& MANIN, 1999). Como a grande maioria dos senadores suplentes no Brasil não conta com experiência política anterior, raros são os casos em que eles se candidatam na eleição subsequente. Com isso, além de não representarem ninguém, eles não se sentem obrigados a conquistar a simpatia e a confiança do eleitor.

Portanto, não é por acaso que as formas de seleção e de atuação dos senadores suplentes estão sendo questionadas pela imprensa brasileira, ao ponto de serem frequentemente lembradas em uma agenda de reforma política. No entanto, não existe nenhum estudo abrangente e sistemático sobre esses importantes tomadores de decisão. Este artigo pretende contribuir para desvendar quem eles são, como operam e quais são os efeitos de suas ações. Na próxima seção, fazemos uma retrospectiva da legislação que regula a seleção dos suplentes de senadores no Brasil e sua contextualização no mundo. Em seguida, realizamos um levantamento dos candidatos a senador nas duas últimas eleições para o Senado, em 2006 e em 2010. Na $4^{a}$ seção, trabalhamos com o perfil dos senadores (titulares e suplentes) que efetivamente tomaram posse no período compreendido entre 1988 a 2008; nela, procuramos identificar a sua atuação profissional, a distribuição partidária e cargos ocupados anteriormente ao mandato. $\mathrm{Na} 5^{\mathrm{a}}$ seção, avaliamos os impactos exercidos pelos senadores suplentes sobre os resultados alcançados no Legislativo brasileiro. Por fim, apresentamos nossas considerações finais. 


\section{Forma como os suplentes são recrutados}

A escolha dos substitutos de senadores tem sofrido algumas transformações nesses quase dois séculos de funcionamento da nossa Câmara Alta. A Constituição de 1824 previa que as vagas seriam preenchidas da mesma forma que o recrutamento original, isto é: o imperador escolhia o novo senador a partir de uma lista tríplice elaborada pelas províncias ${ }^{1}$. A primeira Constituição Republicana (1891) criou a fórmula de nova eleição para suprir as vacâncias, determinando que o eleito exercesse o mandato pelo tempo que restava ao senador que foi substituído².

A Constituição de 1946 definiu que cada senador titular seria eleito junto com um suplente, que o substituiria no caso de licença ou do cargo tornar-se vago. Caso não houvesse suplente e faltasse mais de nove meses para encerramento do mandato, seria providenciada nova eleição ${ }^{3}$. A prática foi mantida na Constituição de $1967^{4}$. Em abril de 1977, o governo militar lançou um pacote de medidas que aumentou o número de suplentes de um para dois, definindo que seriam o segundo e o terceiro candidatos mais votados do mesmo partido ${ }^{5}$. A Constituição de 1988 retomou a fórmula de 1946, que vinculava o titular ao suplente por meio de uma única escolha, e manteve o número de dois suplentes ${ }^{6}$.

Atualmente, os suplentes tomam posse no caso de o titular abandonar o mandato por ter sido eleito para outro cargo, renúncia, morte, doença, cassação, exercício de postos no Executivo. Não existe qualquer limite de tempo para o exercício do cargo, a não ser a duração do mandato do titular. Há casos em que o suplente chega a exercê-lo por quase todo o período de incumbência . É o caso de Gim Argelo, substituto do ex-senador Joaquim Roriz, que renunciou logo no início do mandato, com o intuito de evitar a cassação. O senador Sibá Machado exerceu o cargo de janeiro de 2003 até maio de 2008, em substituição à senadora Marina Silva, que se ausentou para exercer a função de ministra do Meio Ambiente do governo Lula. Outro exemplo de longo mandato como suplente é o do senador Flexa Ribeiro, que permaneceu nele por seis anos, embora tivesse perdido a eleição para o mesmo posto, quando foi candidato em 1994.

A ocorrência de senadores não eleitos não é tão infrequente quanto parece. Ela está presente em 31 das 77 Câmaras Altas existentes hoje no mundo, onde são escolhidos por primeiros-ministros, presidentes, monarcas, pelas assembleias estaduais e até mesmo pela Câmara Baixa. Em 21 delas, essa é a única forma de seleção; nas outras 10, apenas uma parte pequena é escolhida por meio desse procedimento (IPU, 2011). No entanto, isso acontece em países parlamentaristas e semipresidencialistas, onde as Câmaras Altas contam com poderes substancialmente menores. Em países presidencialistas, os senados são fortes e eleitos diretamente pela população (NEIVA, 2006); a única exceção é a do Senado de Burundi, onde os ex-presidentes têm direito ao cargo vitalício de senador e três vagas são destinadas para a minoria étnica "Batwa". Outras experiências aconteceram no Brasil e

\footnotetext{
1 Artigos 43 e 44 da Constituição Politica do Imperio do Brazil, Brasil (1823).

2 Artigo 31 da Constituição da República dos Estados Unidos do Brasil, Brasil (1891).

3 Artigo 52 da Constituição dos Estados Unidos do Brasil, Brasil (1946).

4 Artigo 38 da Constituição da República Federativa do Brasil, Brasil (1967).

5 Artigo 2 do decreto-lei 1.543, de 15.04.77, Brasil (1977).

6 Artigo 45 da Constituição da República Federativa do Brasil, Brasil (1988).

7 Isso não acontece nos Estados Unidos, por exemplo, onde os suplentes são escolhidos pelos governadores, mas perdem o mandato na eleição subsequente; como o Senado, naquele país, é renovado em $1 / 3$ a cada 2 anos, em geral, o substituto permanece pouco tempo na Casa.
} 
NEIVA, P.; IZUMI, M. Os sem-voto do legislativo brasileiro: quem são os Senadores...

no Chile em períodos não democráticos, quando os presidentes podiam nomear senadores (9 no Chile e $1 / 3$ de toda a Casa no Brasil), com o intuito de garantir maiorias no Legislativo.

Em países presidencialistas e democráticos, a existência de senadores "sem voto" já não é tão comum, seja na condição de titular, seja como substituto. Em 18 dos 26 países onde os titulares são escolhidos pelo voto direto $^{8}$, os suplentes também o são, na mesma época, por meio da convocação de nova eleição ou na próxima eleição previamente agendada (uma relação da forma de recrutamento dos senadores substitutos nesses 18 países pode ser vista no Apêndice). Apenas no Brasil, os suplentes são escolhidos pessoalmente pelos próprios titulares ou pelos respectivos partidos. Ao contrário de todos os outros candidatos a cargos eletivos no país, não recebem um único voto dos eleitores e só se tornam conhecidos quando aparecem para substituir os respectivos titulares do cargo.

O problema foi minimizado a partir de resolução expedida pelo Tribunal Superior Eleitoral (TSE), que passou a valer já na última eleição. A nova regra prevê que as urnas eletrônicas mostrem o nome e a foto dos suplentes, juntamente com a dos respectivos candidatos a titular. Não deixa de ser um avanço, já que o eleitor passou a ter uma primeira noção de quem seriam os substitutos dos representantes que ele escolheu. No entanto, a mudança ainda é insuficiente, pois eles continuam não aparecendo durante a campanha eleitoral. Nem mesmo o tão completo sítio do Tribunal na internet disponibilizou essa informação.

Há quem defenda que os suplentes são eleitos, sim, juntamente com os titulares, mesmo antes da obrigatoriedade de ter o nome e a foto constando na cédula eleitoral. Segundo tais defensores, quase sempre juristas, a prática obedece ao mesmo princípio dos candidatos a vice em outras eleições majoritárias, tais como: prefeito, governador e presidente da República. No entanto, existe uma grande diferença entre os dois grupos. Em primeiro lugar, ao contrário dos suplentes de senadores, esses últimos tomam posse e exercem o mandato simultaneamente com o titular, têm atribuições e responsabilidades específicas e recebem salários e vantagens inerentes ao cargo. Além disso, eles são conhecidos do eleitor e costumam participar ativamente da campanha, em debates, comícios, carreatas e propagandas eleitorais.

O eleitor minimamente informado sabia que o vice da candidata a presidente da República em 2010, Dilma Roussef, era o deputado Michel Temer. Muitos sabiam que o candidato a vice-presidente na chapa de José Serra era o deputado Índio da Costa, ainda que ele fosse um simples desconhecido minutos antes de sua escolha como candidato ao cargo. No nível estadual, muitos eleitores do Distrito Federal sabiam que os deputados Tadeu Filippelli e Jofran Frejat eram os candidatos a vice de Agnelo Queiroz e de Joaquim Roriz, respectivamente. Em Minas Gerais, Patrus Ananias e Alberto Pinto estiveram presentes na disputa ao governo do estado, como vices de Hélio Costa e Antônio Anastasia, respectivamente. Por outro lado, poucos saberiam dizer quem eram os suplentes de Cristóvam Buarque de Aécio Neves, senadores eleitos pelo Distrito Federal e pelo estado de Minas Gerais ${ }^{9}$, respectivamente.

\footnotetext{
${ }^{8} \mathrm{~A}$ escolha de aproximadamente $70 \%$ das Câmaras Altas é realizada por meio de eleição (direta ou indireta); os $30 \%$ restantes são escolhidos de diversas outras formas: pelo rei, pelas assembleias estaduais, pelo chefe de governo, pelos conselhos locais, por colégios eleitorais (IPU, 2011).

${ }^{9}$ A propósito, os suplentes do senador eleito Cristóvam Buarque são o funcionário público Wilmar Lacerda, que nunca ocupou cargo eletivo, e o presidente do PRB-DF, Roberto Wagner. Os suplentes de Aécio Neves são o deputado estadual Zezé Perrela e a vereadora de Belo Horizonte, Elaine Matozinhos.
} 
OPINIÃO PÚBLICA, Campinas, vol. 18, no 1, Junho, 2012, p. 1-21

A falta de regras claras permitiu que práticas questionáveis fossem utilizadas para a escolha dos suplentes de senadores. A parca literatura a respeito sugere que eles são escolhidos a partir de quatro motivações principais. Uma delas é a mesma adotada para a escolha de quase todos os vices de governadores, prefeitos e presidente da República: a acomodação dos partidos que fazem parte da aliança eleitoral. Outros critérios menos nobres também costumam ser seguidos: o afetivo (escolha de parentes); a retribuição aos financiadores de campanha; a mera casualidade ${ }^{10}$ e até mesmo acordo para divisão do mandato ${ }^{11}$ (MORAES, 2006; OLIVEIRA, 2005; PESSANHA \& BACKES, 2007; RUDY, 2004; WEFFORT, 2009).

O teste efetivo dessas hipóteses não é fácil. Além da existência do chamado "caixa 2", muitas doações são feitas por empresas, cujos proprietários não são facilmente perceptíveis. Muitas vezes, elas são direcionadas para os partidos e/ou para os comitês eleitorais, cujos repasses não é possível identificar. Acontece também de o suplente não fazer a doação diretamente no seu nome, mas através de outra pessoa, como forma de evitar a exposição do problema, que vem se tornando evidente. Uma outra dificuldade para o teste definitivo da hipótese é que o valor das doações varia enormemente; não se pode colocar no mesmo patamar um doador que participa com menos de um por cento dos recursos arrecadados pelo candidato com outro que financia mais da metade da campanha. Não obstante, notícias veiculadas na imprensa dão conta que a prática não é pouco comum. De acordo com o sítio "Congresso em Foco", um em cada três dos senadores recentemente eleitos recebeu doações de seus suplentes.

No caso dos suplentes escolhidos pelo critério de parentesco, a frequência também parece expressiva. De acordo com a revista Veja (de 22.07.98), entre os 40 postulantes com condições de obter uma das 27 cadeiras em disputa em 1998, 9 (22,5\%) entregaram a suplência a um parente.

Depois dos escândalos que assolaram o Senado nos últimos anos, a imprensa tem centrado o foco sobre os trabalhos da instituição e o comportamento dos seus membros ${ }^{12}$. A discussão sobre os suplentes entra nesse contexto, provocando a apresentação de diversas propostas para mudar a sistemática atual ${ }^{13}$. Diante da pressão popular, a regra deve acabar sendo mudada, mas não se trata de tarefa fácil. Afinal, será necessária a anuência dos próprios suplentes e também dos senadores titulares, que perderão a sua autoridade sobre o cargo quando forem afastados dele.

\footnotetext{
10 Exemplo de escolha casual é a do ex-governador de Roraima, Hélio Campos (PMN), abandonado por aliados políticos que se recusaram a financiar a sua campanha. Às vésperas do prazo final para registro de candidaturas, e sem tempo para fazer uma composição política, ele colocou como seus suplentes o pedreiro João França e o marceneiro Claudomiro Pinheiro, que trabalhavam em uma obra em sua casa. Campos faleceu dois meses depois da posse, dando a João França o privilégio de ser senador por quase um mandato inteiro de oito anos (RUDY, 2004; BOAVENTURA E LIMA, 2004). Em Minas Gerais, o caso mais pitoresco foi o da ex-secretária do PTB, Regina Assumpção, que assumiu o cargo de senadora por dois anos quando o titular, Arlindo Porto, virou ministro da Agricultura. Como Porto só decidiu se candidatar na última hora, acabou colocando a secretária do partido como suplente. O segundo suplente era o office-boy do escritório do PTB, em Belo Horizonte.

11 Por exemplo, segundo a revista Veja (04.03.04), o senador Saturnino Braga teria assinado um contrato para deixar o mandato na sua metade, quando assumiria o seu suplente, Carlos Lupi. Como o titular nunca saiu do cargo, Lupi resolveu denunciar o caso. Relato análogo foi feito pelo senador Valdir Raupp, que afirmou ter recebido proposta de um empresário para comprar a sua suplência pelo valor de R\$1,5 milhão (Folha de São Paulo, 15.01.07).

12 Sobre escândalos no Senado, veja Chaia e Teixeira (2001).

13 Entre outras, as seguintes propostas têm sido levantadas: proibição da escolha de parentes ou do cônjuge; eleição direta dos suplentes, juntamente com o titular ou no pleito imediatamente subsequente ao aparecimento da vaga; ocupação da vaga pelo deputado federal mais votado no estado e que seja do mesmo partido do titular; eleição de apenas um suplente (hoje são dois); exposição dos suplentes durante a campanha eleitoral, com o mesmo destaque que é dado para os titulares.
} 
NEIVA, P.; IZUMI, M. Os sem-voto do legislativo brasileiro: quem são os Senadores...

Enquanto não muda, continuará havendo no Senado duas classes distintas de legisladores: um grupo de elite, respaldado pela escolha de parcela substantiva da população e composto por importantes lideranças regionais e nacionais, muitas delas ex-governadores, ex-ministros e até ex-presidentes da República. De outro lado, os suplentes, quase sempre ilustres desconhecidos dos eleitores, mas que podem fazer alguma diferença nos trabalhos da Casa. Sendo assim, conhecê-los passa a ser tarefa privilegiada da Ciência Política. Na próxima seção, iniciamos essa tarefa pelo período eleitoral, isto é, procurando identificar o perfil dos pretendentes ao cargo.

\section{Perfil dos candidatos a senador e de seus respectivos suplentes}

Nesta seção, trabalhamos com os candidatos a senador nas eleições de 2006 e 2010 e seus respectivos suplentes. Informações sobre eleições costumam ser imprecisas e cercadas de mistério. Por causa disso, os dados que apresentamos não vão muito além de indícios potenciais de financiamentos de campanha dos titulares por parte dos respectivos suplentes e de relações familiares entre eles. $\mathrm{Na}$ Tabela 1, comparamos dados pessoais, profissionais e financeiros das três categorias que estão sendo analisadas: titulares, primeiros suplentes e segundos suplentes de senador.

\section{Tabela 1}

Perfil de Candidatos a Senador, Titulares e Suplentes Eleições 2006 e 2010

\begin{tabular}{|c|c|c|c|c|c|c|c|}
\hline Cargo & $\begin{array}{l}\text { Média } \\
\text { de } \\
\text { idade }\end{array}$ & $\begin{array}{l}\text { Mulheres } \\
\text { (\%) }\end{array}$ & $\begin{array}{c}\text { Nasceram } \\
\text { no estado* } \\
(\%)\end{array}$ & $\begin{array}{c}\text { Têm Curso } \\
\text { Superior (\%) }\end{array}$ & $\begin{array}{c}\text { Empresários } \\
\text { (\%) }\end{array}$ & $\begin{array}{l}\text { Patrimônio } \\
\text { médio } \\
\text { (mil reais)* }\end{array}$ & $\mathbf{N}$ \\
\hline Senador & 52,7 & 14,2 & 74,8 & 72,0 & 5,5 & 2.305 & 436 \\
\hline $\begin{array}{l}1^{\circ} \text { Suplente } \\
\text { Senador }\end{array}$ & 50,9 & 18,9 & 70,4 & 63,2 & 12,7 & 7.503 & 440 \\
\hline $\begin{array}{l}2^{\circ} \text { Suplente } \\
\text { Senador }\end{array}$ & 51,1 & 24,7 & 73,3 & 57,1 & 9,0 & 3.210 & 434 \\
\hline
\end{tabular}

Fonte: TSE. Resultados calculados pelos autores. (*) Dados disponíveis apenas para a eleição de 2010.

A Tabela 1 mostra que não existe uma distância muito grande entre a média de idade de candidatos a Senadores titulares e suplentes, mas eles diferem em vários outros aspectos. É perceptível o percentual maior de candidatas do sexo feminino entre os concorrentes a suplente; ainda que não comprove, a informação sugere uma confirmação da hipótese da escolha de parentes para a suplência, especialmente esposas. Observa-se também uma proporção levemente maior de nativos do estado entre os candidatos a titulares, em relação aos candidatos a suplentes. É visível a diferença no nível de instrução: $72 \%$ dos candidatos a titular têm curso superior, contra apenas $57 \%$ dos $2^{\circ}$ suplentes e $63 \%$ dos $1^{\circ}$ suplentes com esse nível de formação. Apesar de ser essa uma indicação de que os detentores do cargo têm melhor formação técnica do que os seus substitutos, é preciso lembrar que tais dados 
OPINIÃO PÚBLICA, Campinas, vol. 18, no 1, Junho, 2012, p. 1-21

referem-se aos candidatos e não aos políticos eleitos. Entre esses últimos, a literatura tem mostrado uma proporção maior de legisladores com curso superior ${ }^{14}$.

Os dados mais importantes dizem respeito ao status socioeconômico dos candidatos. 0 percentual de empresários entre os aspirantes a $2^{\circ}$ suplente é de $9 \%$ e a $1^{\circ}$ suplente de $12,7 \%$, percentuais substancialmente maiores do que o encontrado entre os candidatos a senador titular (5,5\%). Trata-se da maior frequência entre todas as categorias de profissionais que se apresentaram nas duas últimas eleições, para todos os cargos. Os primeiros suplentes destacam-se também em termos de patrimônio médio, que ficou em um patamar acima de $\mathrm{R} \$ 7$ milhões de reais, três vezes maior do que média do patrimônio de um candidato titular a senador.

Esses números não são suficientes para confirmar a suspeita de que os suplentes de senadores financiam as campanhas de seus respectivos titulares, até por que os dados sobre patrimônio estão restritos a uma única eleição. Porém, eles reforçam tal hipótese; é mais razoável pensar que os empresários e as pessoas que contam com mais recursos tendam a destinar mais recursos para esse tipo de iniciativa do que outras categorias profissionais ou menos abastadas. Cabe acrescentar que, em média, uma campanha para senador custa bem mais do que uma campanha para deputado: segundo Lemos, Marcelino e Pederiva (2010), a proporção entre as duas foi de 25,5\% em 2002 e de 31,1\% em 2006.

Esses dados expõem uma radiografia parcial da situação. É importante verificar também se o quadro muda de acordo com a coloração ideológica/partidária dos suplentes. No Gráfico 1 , apresentamos a proporção de empresários entre os candidatos a suplente de senador, por partido político.

\section{Gráfico 1}

Proporção de Empresários Candidatos a Suplente de Senador, por Partido

Eleição 2010

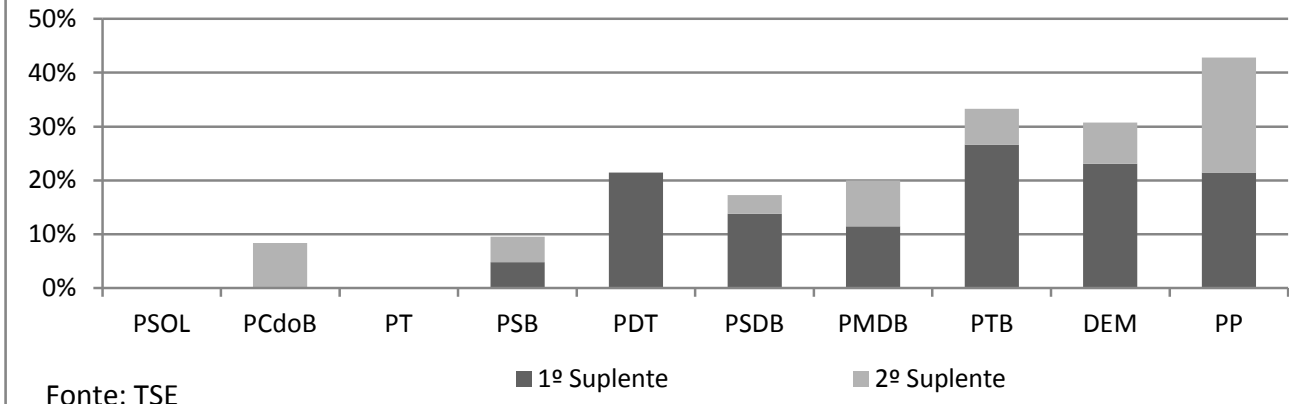

Fonte: TSE

2은 Suplente

\footnotetext{
${ }^{14}$ Santos (2000) identificou um percentual de $84 \%$ de formação superior entre os deputados federais no período de 1987 a 1999; Perissinoto e Miríade (2009) verificaram que 80,5\% tinham esse nível de formação entre os eleitos em 2006 . Para o Senado, Lemos e Ranincheski (2003) encontraram as surpreendentes proporções de 97,6\%, 95\% e 98\%, nas legislaturas que iniciaram em 1991, 1995 e 1999, respectivamente.
} 
NEIVA, P.; IZUMI, M. Os sem-voto do legislativo brasileiro: quem são os Senadores...

O Gráfico 1 mostra que a proporção de empresários entre os suplentes de senadores aumenta à medida que se caminha da esquerda para a direita no espectro político. Os partidos mais à esquerda (PSOL, PC do B, PT e PSB) apresentaram frequência nula, ou muito baixa. Nos partidos de centro (PSDB e PMDB), sua presença foi um pouco maior, mas não tão grande: em torno de $15 \%$ a 20\%. Já nos partidos de direita (PTB, DEM e PP), a decisão de escolher empresários como suplentes foi clara: mais de $30 \%$ deles faziam parte dessa categoria profissional. A estratégia é ainda mais evidente no caso dos primeiros suplentes: a sua proporção ficou sempre acima de $20 \%$. Quando se avalia a parcela de empresários apenas entre eles mesmos, desconsiderando os segundos suplentes, os números aproximam-se da metade: PTB (57\%), DEM (43\%), PP (50\%).

Alguém poderia argumentar que essa é uma característica dos candidatos dos partidos conservadores em geral, para todos os cargos, e não apenas para a escolha dos senadores suplentes. Segundo Santos e Serna (2007), tais legendas tendem a apresentar padrões de recrutamento social mais elitista, compondo suas bancadas entre proprietários rurais e urbanos. De fato, os partidos conservadores de direita apresentaram uma proporção maior de empresários como candidatos. No entanto, ela é bem mais expressiva entre os suplentes, conforme aponta o Gráfico 2.

Gráfico 2

Empresários Candidatos, por Partido

\section{Eleição 2010}

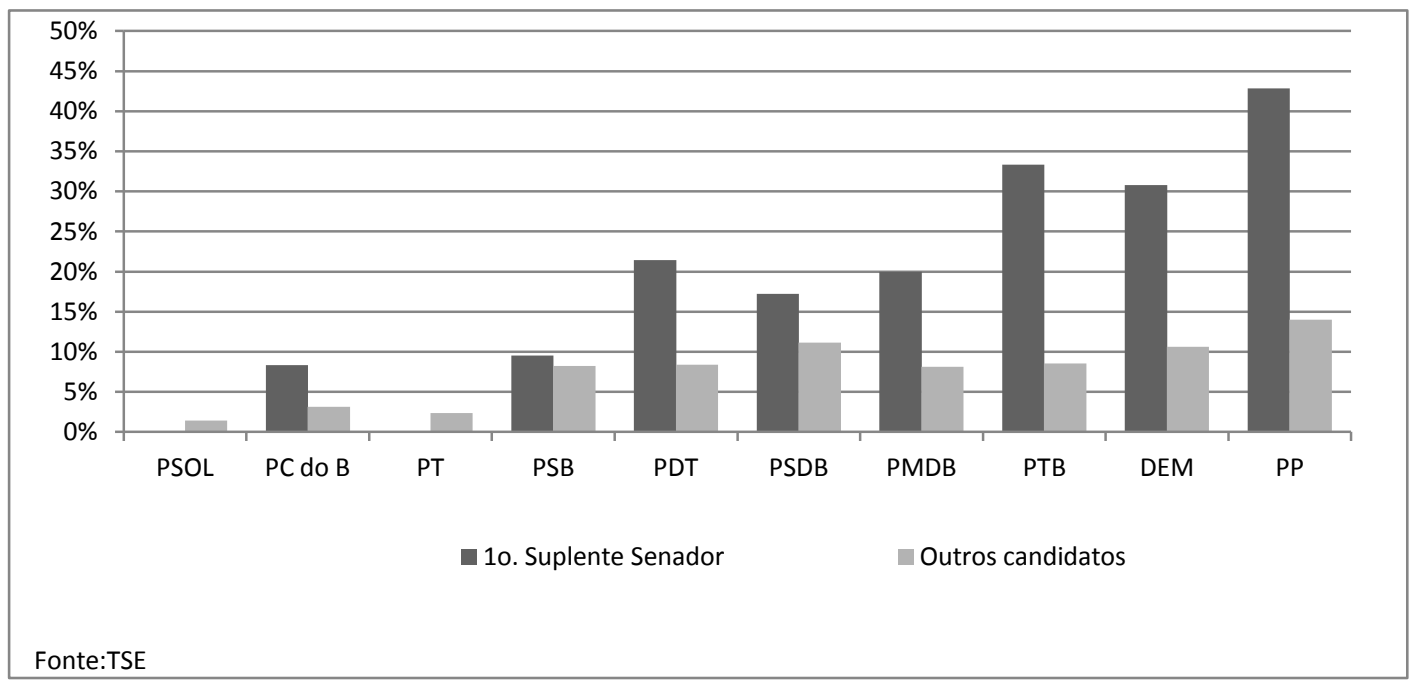

As informações apresentadas na Tabela 1 e no Gráfico 2 mostram que os candidatos a suplente de senador fazem parte de uma elite econômica. No entanto, dados desse tipo só estão disponíveis para uma eleição, o que limita muito a nossa capacidade de inferência e de generalização. Além disso, as informações dizem respeito aos candidatos em geral, e não apenas aos que foram eleitos. De agora em 
OPINIÃO PÚBLICA, Campinas, vol. 18, no 1, Junho, 2012, p. 1-21

diante, limitaremos a nossa análise a esses últimos, isto é, aos senadores que foram efetivamente "escolhidos", titulares e suplentes.

\section{Perfil dos senadores titulares e suplentes que efetivamente tomaram posse}

Nesta seção, trabalhamos apenas com os senadores efetivos, isto é, aqueles que foram selecionados e chegaram a tomar posse nos vinte e um anos compreendidos entre 1998 a 2008, tanto titulares quanto suplentes. Na Tabela 2, apresentamos a sua distribuição profissional, tomando como base a ocupação principal.

Tabela 2

Perfil de senadores titulares e suplentes que tomaram posse entre 1988 e 2008

\begin{tabular}{|l|c|c|}
\hline Profissão & Suplentes & Titulares \\
\hline Empresário & $34,5 \%$ & $21,9 \%$ \\
\hline Advogado/Juiz & $14,4 \%$ & $19,6 \%$ \\
\hline Profissional da Saúde & $9,4 \%$ & $8,7 \%$ \\
\hline Outros Profissionais Liberais & $7,9 \%$ & $12,8 \%$ \\
\hline Professor & $5,0 \%$ & $8,2 \%$ \\
\hline Economista & $4,3 \%$ & $4,1 \%$ \\
\hline Trabalhador & $4,3 \%$ & $3,7 \%$ \\
\hline Comunicador & $2,9 \%$ & $9,1 \%$ \\
\hline Funcionário Público & $0,7 \%$ & $9,1 \%$ \\
\hline Outros & $4,3 \%$ & $2,7 \%$ \\
\hline Sem Informação & $12,2 \%$ & $0,0 \%$ \\
\hline N & 139 & 219 \\
\hline
\end{tabular}

Os dados da Tabela 2 reforçam as conclusões a que havíamos chegado a partir das informações sobre os candidatos. Quando analisamos os senadores titulares e suplentes que efetivamente tomaram posse, verificamos que existe uma proporção substancialmente maior de empresários entre os últimos. Eles respondem por mais de um terço das vagas ocupadas no período compreendido entre 1988 e 2008. O número é alto tanto em comparação com os senadores titulares, que não passaram de $22 \%$, quanto em comparação com outras profissões. O percentual de empresários entre os suplentes chega a ser mais do que o dobro do percentual de advogados, que é uma outra profissão bastante comum em parlamentos do mundo ocidental (COTTA \& BEST, 2007; URIARTE, 1997; WEBER, 1999). Por outro lado, a proporção de suplentes é baixa entre as profissões que favorecem uma grande exposição popular, tais como professores, comunicadores e funcionários públicos.

No entanto, se suplentes de senadores fazem parte de uma elite econômica, o mesmo não acontece na esfera política. Nada menos do que 58\% deles nunca exerceram qualquer cargo eletivo, contra $14 \%$ dos titulares. No que diz respeito aos cargos não eletivos, a diferença entre as duas 
NEIVA, P.; IZUMI, M. Os sem-voto do legislativo brasileiro: quem são os Senadores...

categorias é menor, mas também expressiva: 73\% e 47\%, respectivamente. Uma descrição mais detalhada pode ser vista no Gráfico 3.

\section{Gráfico 3}

Percentual de cargos eletivos e não eletivos ocupados por senadores titulares e suplentes anteriormente ao mandato

\begin{tabular}{|c|c|c|}
\hline \multirow{2}{*}{$\begin{array}{r}\text { vereador } \\
\text { prefeito }\end{array}$} & 14,4 & 17,4 \\
\hline & 13,7 & 29,2 \\
\hline \multirow{4}{*}{$\begin{array}{r}\text { deputado estadual } \\
\text { deputado federal } \\
\text { senador } \\
\text { governador }\end{array}$} & 21,6 & 34,2 \\
\hline & 15,1 & 54,3 \\
\hline & 2,9 & 25,1 \\
\hline & 2,9 & 31,5 \\
\hline \multirow{5}{*}{$\begin{array}{r}\text { secretário municipal } \\
\text { secretário estadual } \\
\text { presidente estatal } \\
\text { ministro }\end{array}$} & 6,5 & 9,6 \\
\hline & 15,8 & 26,5 \\
\hline & 4,3 & 16,4 \\
\hline & 5,0 & 18,7 \\
\hline & Suplente & Titular \\
\hline
\end{tabular}

$\mathrm{Na}$ parte superior do Gráfico 3, os dados mostram que poucos suplentes de senadores ocuparam cargos eletivos antes de substituírem os titulares. Ainda assim, em funções menos importantes, como as de vereador, prefeito e deputado estadual. Entre os titulares, a situação é bem diferente. A sua experiência eleitoral é bem maior, especialmente para os cargos mais importantes: mais da metade já foi deputado federal, 25\% já foram senadores e 31,5\% já foram governadores do seu estado; entre os suplentes, os números são bem mais baixos: 13\%, 3\% e 1\%, respectivamente.

No que se refere à ocupação de cargos não eletivos, a diferença entre titulares e suplentes é um pouco menor, mas cresce à medida que aumenta a sua importância. No relevante cargo de ministro de Estado, apenas 5\% dos suplentes passaram por ele, contra $19 \%$ dos senadores titulares. Já no cargo menos importante de secretário municipal, a distância entre eles é pequena: 14\% dos suplentes tiveram essa experiência, contra $17 \%$ dos titulares.

Apesar de encontrarmos algumas regularidades, os suplentes não formam um grupo homogêneo. A diferença entre eles fica mais evidente quando são segmentados pelos partidos políticos, a começar pela frequência com que exercem o cargo em substituição ao senador titular. Para observá-la, decidimos computar os votos dados por titulares e suplentes no plenário do Senado no período 1989 a 2008. Consideramos ser essa uma medição mais precisa do grau de participação nos trabalhos da Casa 
do que a contagem do número de dias que lá permaneceram. Os resultados podem ser vistos no Gráfico 4.

\section{Gráfico 4}

Proporção de votos dados por titulares e suplentes, por partido

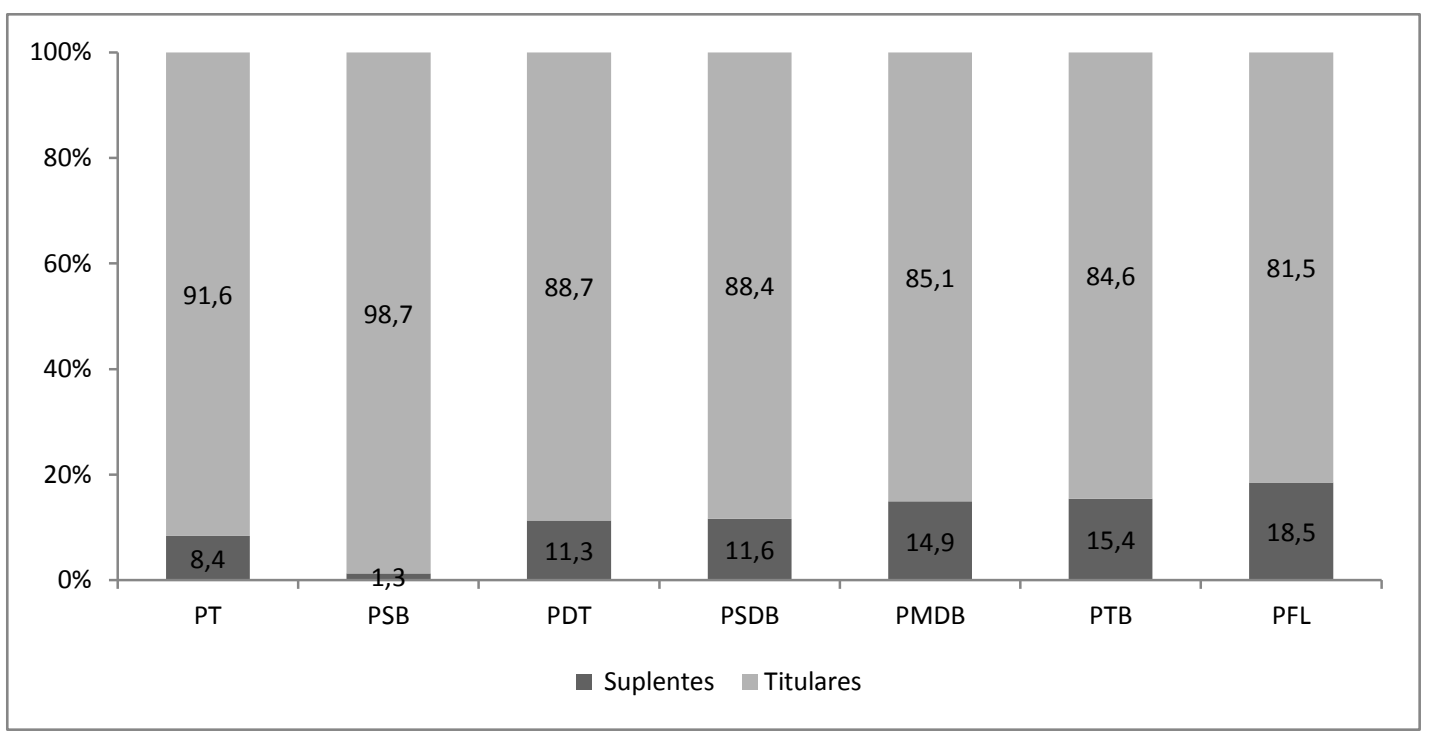

A distribuição observada no Gráfico 4 revela que, no período analisado, os suplentes estiveram mais presentes nos partidos de direita do que nos de esquerda. No PFL, eles responderam por aproximadamente $19 \%$ dos votos; no PT, foram responsáveis por pouco mais de $8 \%$ dos votos e no PSB quase não apareceram. Esses dados corroboram os achados de Moraes (2006), que encontrou números ainda mais surpreendentes para um momento específico: segundo o autor, $41 \%$ dos senadores do PFL tinham suas vagas ocupadas por suplentes em fevereiro de 2002, contra $17 \%$ do PMDB, $19 \%$ do PSDB e $7 \%$ no Bloco de Oposição. Em parte, isso é explicado pelo fato de que os senadores de esquerda não ocuparam cargos no Executivo federal durante 16 anos da nossa amostra (de 1989 a 2002), não abrindo vagas para os seus suplentes. Já o PMDB e PTB fizeram parte de quase todas as coalizões de governo e o PFL, finalmente, não participou do governo Lula.

Impacto dos senadores suplentes sobre os resultados políticos

Segundo Ferreira (2008), entre os anos de 1995 e 2008, 174 suplentes de senadores exerceram mandato. No nosso banco de dados, identificamos 139 suplentes para o período de 1989 a $2008^{15}$. Com frequência, eles chegam a representar mais de $20 \%$ dos senadores. Por exemplo, em novembro de 2009, 23\% das cadeiras estavam sendo ocupadas pelos suplentes. No mesmo período, o

${ }^{15}$ Provavelmente, a diferença decorre do fato de que consideramos apenas aqueles que chegaram a se manifestar em alguma votação nominal. 
NEIVA, P.; IZUMI, M. Os sem-voto do legislativo brasileiro: quem são os Senadores...

percentual na Câmara dos Deputados não chegava a $11 \%$. Uma possível explicação para isso é que a média de idade dos senadores é mais elevada do que a dos deputados ${ }^{16}$, o que faz com que haja mais afastamentos por motivo de doenças e de óbitos no Senado do que na Câmara ${ }^{17}$. Outra explicação é que, por estarem em um patamar superior da carreira política, muitos senadores são requisitados para ocupar cargos no Executivo Federal ${ }^{18}$, especialmente de ministros, abrindo vaga para os suplentes. Nos Estados Unidos, onde a prática não é comum, a presença de senadores substitutos é muito menor: apenas 184 em um século de história (NEALE, 2009).

Um segundo aspecto que torna a presença dos suplentes no Senado relevante é que eles podem exercer qualquer atividade e ocupar qualquer cargo, como se titulares fossem. Entre outras, eles podem assinar pedido de informação ao Executivo, apresentar projetos de lei e emendas, votar, participar de comissões, realizar discursos, presidir comissões parlamentares de inquérito, participar do Conselho de Ética. Enfim, os suplentes podem executar todas as atribuições que têm os senadores titulares. Isso não acontece na Câmara dos Deputados, onde os suplentes não podem ocupar cargos na Mesa Diretora, nem de presidente ou de vice-presidente de comissão ${ }^{19}$, embora lá eles tenham sido eleitos com o respaldo das urnas.

Como os suplentes de senadores não têm que prestar contas ao eleitorado, podem ser utilizados para tarefas embaraçosas, que poderiam gerar impacto eleitoral negativo para os senadores titulares. É o que aconteceu com o senador Paulo Duque, que presidiu o Conselho de Ética quando apareceram as denúncias contra o então presidente da instituição, José Sarney; de João Pedro, que comandou a Comissão Parlamentar de Inquérito destinada a investigar irregularidades na Petrobrás; do senador Wellington Salgado, que foi um dos mais fervorosos defensores do senador Renan Calheiros, quando esse esteve ameaçado de ser cassado por quebra de decoro parlamentar. Salgado exerceu, inclusive, o cargo de relator no Conselho de Ética da Instituição, que teve como um de seus presidentes o também suplente Sibá Machado (PT.AC).

Um complicador a mais é que a desproporcionalidade de representação estadual é muita alta no Brasil, uma das maiores do mundo (SAMUELS \& SNYDER, 2001; STEPAN, 1999). Ela faz com que senadores eleitos com 9 ou 10 milhões de votos tenham o mesmo peso daqueles que são eleitos com pouco mais de 200 mil. Pior, valem o mesmo que o voto de um senador suplente, que não recebeu nenhum voto nas urnas. Para citar um exemplo: na votação que acabou com a cobrança da CPMF em 2009, os votos contrários dos suplentes Adelmir Santana, Flexa Ribeiro e João Tenório tiveram o mesmo peso dos votos favoráveis dos titulares Eduardo Suplicy e Aloizio Mercadante, cuja soma de votos nas urnas aproximou-se de 21 milhões.

Em uma análise sobre os efeitos causados por tipos específicos de legisladores, é fundamental verificar como lidam com o ator principal na política brasileira: o Poder Executivo. A literatura tem

${ }^{16}$ Conforme vimos na Tabela 1, a média de idade dos candidatos a deputado federal em 2010 foi de 48,1 anos; a de senador, 53,5 anos.

17 A partir de levantamento próprio feito nas páginas do Senado e da Câmara dos Deputados na internet, verificamos as seguintes taxas de óbito na última legislatura (até 01.11.10): 5 senadores (6,2\% do Senado); 14 deputados (2,7\% da Câmara).

18 De fato, conforme mostra D' Araújo (2007), uma proporção bem maior de senadores ocupou cargos de ministros vis-à-vis a proporção de deputados, no período de 1995 a 2006. Como o Senado é uma casa bem menor do que a Câmara, os 46 senadores que participaram dos gabinetes nesse período corresponderam a 9,5\% da Casa; já na Câmara, os 103 deputados representaram apenas $3,3 \%$.

${ }^{19}$ Artigo 243 do Regimento Interno. 
mostrado que esse predomina nas decisões de voto dos parlamentares (CHEIBUB, FIGUEIREDO, \& LIMONGI, 2002; FIGUEIREDO \& LIMONGI, 1996, 1999). No presente artigo, as perguntas que se colocam são: os suplentes apresentam uma postura diferenciada perante o Executivo? A despeito dos partidos, o seu grau de cooperação é maior? Em que circunstâncias? Iniciamos essa discussão a partir dos dados da Tabela 3.

\section{Tabela 3}

\section{Apoio de Senadores Titulares e Suplentes ao Governo (\%) 1989 a 2008}

\begin{tabular}{|c|c|c|}
\hline & Suplentes & Titulares \\
\hline Não Apoiam & 12,0 & 18,6 \\
\hline Apoiam & 88,0 & 81,4 \\
\hline Total & 100 & 100 \\
\hline Pearson chi2(1) $=264.9802$ & $\mathrm{Pr}=0.000$ & $\mathrm{~N}=71.501$
\end{tabular}

Os resultados revelam que o apoio dos suplentes ao governo foi proporcionalmente maior do que o apoio oferecido pelos titulares: $88 \%$ e $81,4 \%$ das vezes, respectivamente. 0 teste de qui-quadrado revela que a diferença não é aleatória, apresentando significância estatística ao nível de 1\%.

Esses números são sugestivos, mas é preciso controlar os efeitos de outras variáveis importantes. A principal delas diz respeito ao aspecto partidário, mais especificamente ao fato de o parlamentar estar filiado a um partido da base de sustentação ao governo. Conforme mostra uma ampla literatura na área, essa é uma referência fundamental para explicar os resultados favoráveis ao Executivo no Congresso. Isso porque o presidente conta com recursos institucionais e de patronagem, que Ihe garantem o controle da agenda. Segundo Santos (2002), por exemplo, o apoio parlamentar e a manutenção da coalizão são viabilizados não apenas em função do grau de concordância dos legisladores com o programa de governo, mas também do acesso a cargos políticos. De acordo com Amorim Neto (2000), o apoio ao Executivo depende, em grande parte, do grau de coalescência do Gabinete, isto é, da proporcionalidade entre as cotas ministeriais dos partidos e seus pesos parlamentares. Figueiredo e Limongi (1999) destacam os poderes legislativos do presidente e o processo decisório centralizado, que coloca amplos poderes nas mãos dos líderes partidários. Pereira e Mueller (2002) acrescentam a utilização das emendas orçamentárias como uma moeda política de baixo custo para ser trocada por apoio político da sua coalizão no Congresso.

Além da referência partidária/coalizional, controlamos o efeito de variáveis relacionadas ao estado de origem do parlamentar, tais como, o Índice de Desenvolvimento Humano (IDH); o grau de urbanização, medido pelo percentual de população urbana e a desproporcionalidade de representação. Essas nos parecem variáveis importantes a serem consideradas na análise de uma Casa Legislativa com perfil federativo e em um país com amplas desigualdades regionais.

$\mathrm{Na}$ Tabela 4, testamos a hipótese de que os senadores suplentes oferecem maior apoio às propostas do Executivo no Congresso, em comparação com os titulares. Além das variáveis 
NEIVA, P.; IZUMI, M. Os sem-voto do legislativo brasileiro: quem são os Senadores...

apresentadas, controlamos também o efeito relativo ao grau de importância da matéria que está sendo decidida: se substantiva ou procedimental. Trata-se de modelos de regressão logística que têm como variável dependente o voto em relação à vontade do governo, codificado como "um" quando favorável e como "zero" quando desfavorável. A exemplo de outros estudos envolvendo votações nominais, excluímos aquelas que apresentaram muito pouca divergência (abaixo de 10\%).

Em virtude da grande desigualdade social e da extrema desproporcionalidade que existe entre as regiões no Brasil, decidimos realizar análises com amostras separadas. No primeiro modelo, foram incluídos todos os senadores. Nos modelos 2 e 3, apenas os senadores das regiões sul/sudeste e norte/nordeste, respectivamente. No Modelo 4, apenas os suplentes.

Tabela 4

Determinantes do apoio dos senadores ao governo 1989-2008

\begin{tabular}{|c|c|c|c|c|}
\hline & $\begin{array}{l}1 \text { Todas as } \\
\text { Regiões }\end{array}$ & 2 Regiões Sul/SE & 3 Regiões N/NE & $\begin{array}{l}4 \text { Só os } \\
\text { Suplentes }\end{array}$ \\
\hline Coalizão de governo & $\begin{array}{l}4,53^{* * * *} \\
(54,81)\end{array}$ & $\begin{array}{l}3,53 * * * \\
(31,19)\end{array}$ & $\begin{array}{l}3,59 * * * \\
(42,82) \\
\end{array}$ & $\begin{array}{l}3,79 * * * \\
(16,16) \\
\end{array}$ \\
\hline IDH & $\begin{array}{l}2,61 * * \\
(2,13) \\
\end{array}$ & - & - & $\begin{array}{l}0,75 \\
(\cdot 0,46) \\
\end{array}$ \\
\hline População Urbana & $\begin{array}{l}0,99 * * * \\
(-3,53)\end{array}$ & - & - & - \\
\hline $\begin{array}{l}\text { Desproporcionalidade } \\
\text { Representação }\end{array}$ & $\begin{array}{l}1,03 * * * \\
(3,88)\end{array}$ & - & - & $\begin{array}{l}1,13 * * * \\
(5,37)\end{array}$ \\
\hline Matéria Substantiva & $\begin{array}{l}0,93 * * * \\
(-2,17) \\
\end{array}$ & $\begin{array}{l}1,72 * * * \\
(9,80) \\
\end{array}$ & $\begin{array}{l}1,93 * * * \\
(16,82) \\
\end{array}$ & - \\
\hline Titular/Suplente & $\begin{array}{l}0,74 * * * \\
(-7,32) \\
\end{array}$ & $\begin{array}{l}0,65 * * * \\
(\cdot 6,87) \\
\end{array}$ & $\begin{array}{l}0,67 * * * \\
(\cdot 8,74) \\
\end{array}$ & - \\
\hline Observações & 29.223 & 15.056 & 32.236 & 3.989 \\
\hline R2 Ajustado & 0,093 & 0,072 & 0,075 & 0,068 \\
\hline Log likelihood & $\cdot 16.436$ & $\cdot 7.560$ & $\cdot 14.360$ & .2 .039 \\
\hline
\end{tabular}

A primeira informação que salta aos olhos na Tabela 4 é a alta significância estatística e o sinal positivo da variável que informa o fato de o parlamentar fazer parte ou não da coalizão de governo. Isso acontece em todos os modelos e não surpreende, tendo em vista uma literatura consolidada sobre o tema que alerta sobre a capacidade do presidente da República aprovar as matérias de seu interesse no Congresso Nacional. Conforme afirma Limongi (2006), a disciplina média em 842 votações realizadas na Câmara dos Deputados foi de $87,4 \%$. De acordo com o autor, o controle da produção legislativa pelo governo é resultado da interação entre poder de agenda e apoio da maioria, reunida por uma coalizão partidária, não muito diverso do que se passa nos regimes parlamentaristas.

A variável que identifica o tipo de matéria que está sendo votada também se apresenta significativa nos três modelos em que foi incluída; porém, ela muda de sinal de um modelo para o outro. 
OPINIÃO PÚBLICA, Campinas, vol. 18, no 1, Junho, 2012, p. 1-21

Outra informação importante diz respeito à desproporcionalidade de representação: quanto mais sobrerrepresentado o estado de origem do senador, maior a chance de ele votar a favor do Executivo. Isso acontece tanto no modelo completo, que envolve todas as variáveis e todas as regiões do país, quanto nos modelos que restringem as regiões.

Os resultados mais importantes para os nossos propósitos são os que testam se o fato de o senador ser titular (codificado como "um") ou suplente (codificado como "zero") faz alguma diferença para os resultados alcançados. Conforme podemos ver, o sinal negativo e a alta significância dos testes mostram que os suplentes, de fato, tendem a votar mais favoravelmente ao governo, mesmo depois de controlarmos pelas variáveis econômicas, demográficas e políticas.

No Modelo 4, realizamos a análise de regressão só com os senadores suplentes. Cabe ressaltar o impacto da variável desproporcionalidade de representação, o que sugere que o governo tem maior suporte dos suplentes dos estados menores. A não significância da variável IDH sugere que o tipo de negociação realizada entre os senadores suplentes e o Executivo não está relacionada com o grau de desenvolvimento do estado.

Esses resultados nos dão uma percepção do comportamento dos senadores no período como um todo. Para se ter uma ideia mais clara do apoio de titulares e suplentes em governos diferentes, apresentamos o percentual médio anual de apoio dado ao longo do tempo.

Gráfico 5

Apoio ao Governo - Titulares e Suplentes (\%)

1989 a 2008

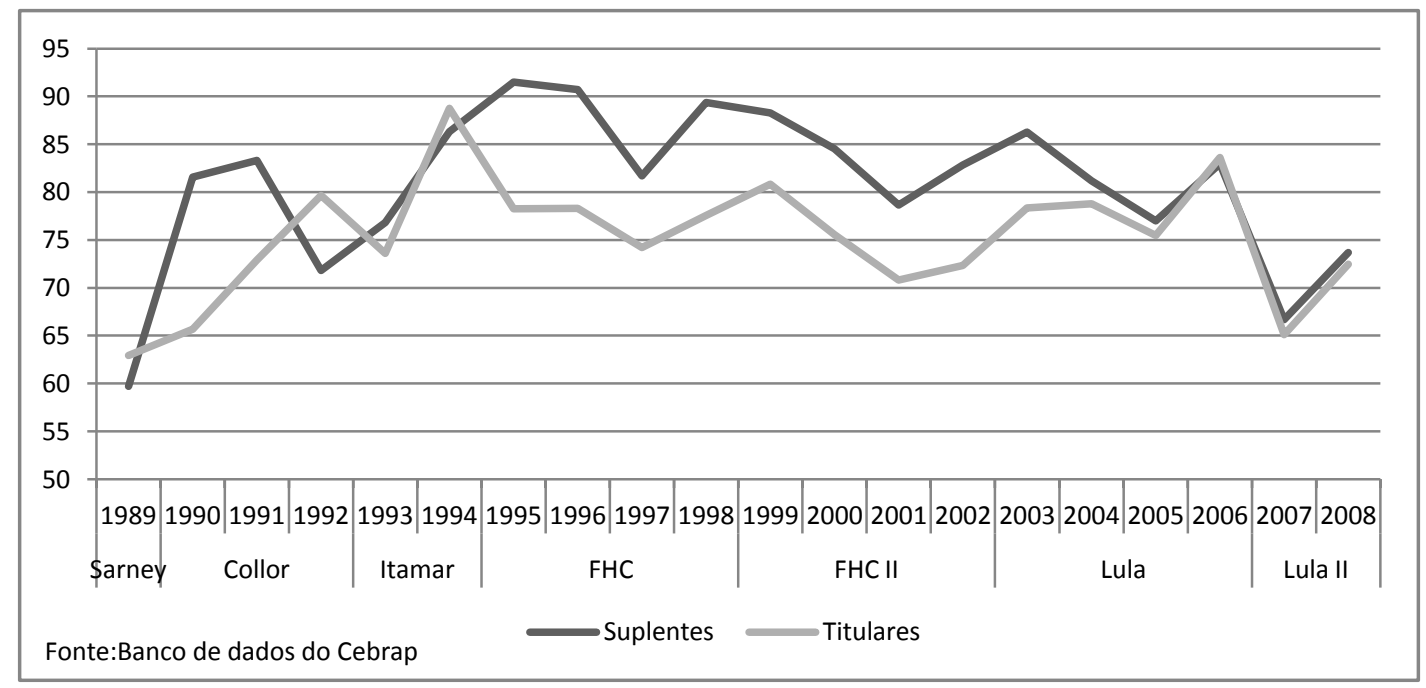

O Gráfico 5 revela que existe diferença entre titulares e suplentes no que se refere ao nível de apoio dado ao Executivo no Senado, mas ela não mantém o mesmo padrão ao longo do tempo. No último ano do governo Sarney, nos dois anos do governo Itamar e durante quase todo o governo Lula, ela 
NEIVA, P.; IZUMI, M. Os sem-voto do legislativo brasileiro: quem são os Senadores...

foi praticamente inexistente. No ano do impedimento de Collor, o apoio dos suplentes chegou a ser menor do que o dos titulares; porém, esse foi um momento atípico da nossa história política, em que poucas matérias foram votadas no Legislativo, o que nos impede de tirar conclusões taxativas a respeito desse momento.

Não há uma explicação evidente para a evolução do apoio. Uma possibilidade pode estar relacionada ao tipo de coalizão partidária existente em cada um dos períodos. Nos governos Collor e Fernando Henrique, a aliança foi feita com partidos de direita, especialmente com o PFL. Já os governos de Sarney, Itamar e Lula tiveram uma participação maior do centro, particularmente do PMDB. É importante lembrar que, conforme vimos no Gráfico 4, os partidos de direita contaram com uma frequência relativamente maior de suplentes, vis-à-vis os partidos de centro e de esquerda.

\section{Considerações Finais}

Neste artigo, buscamos fazer um mapeamento dos suplentes de senadores, uma classe especial de políticos, que não tem recebido a atenção devida da nossa disciplina. Avaliamos a sua carreira política e profissional, a sua distribuição pelos partidos e em governos diferentes, bem como a sua atuação nas decisões tomadas no Senado. Se tivéssemos que criar um "tipo ideal” desses parlamentares, diríamos que seria o de um empresário, rico, com pouca experiência política, filiado a um partido de direita e com tendência a apoiar o Poder Executivo. Obviamente, essa é apenas uma aproximação estilizada para facilitar a nossa análise. É preciso considerar que o grupo dos suplentes é bastante heterogêneo: os que são filiados aos partidos de esquerda parecem distanciar-se dessa idealização, mas a sua diversidade e o número menor de casos dificulta uma padronização.

Os suplentes contam também com uma característica marcante, que os distinguem dos demais ocupantes de cargos eletivos no país: eles não são votados diretamente pelo eleitor, mas devem suas escolhas aos respectivos titulares do cargo. Não foi possível avaliar exaustivamente como são feitas tais escolhas, mas há indícios de que muitos são selecionados por financiarem as campanhas dos titulares, alguns por serem seus parentes, outros em função de alianças eleitorais. Apesar de existirem senadores escolhidos pessoalmente em outros países, eles estão concentrados em sistemas parlamentaristas e semipresidencialistas, onde as Câmaras Altas são fracas. A manutenção de suplentes sem votos em um Senado forte como o brasileiro pode ter consequências danosas para nossa democracia.

A escolha de vários senadores para fazer parte do Gabinete, em número proporcionalmente bem maior do que o de deputados, faz com que o governo conte na Casa com um contingente de suplentes bastante "fiéis". Isso porque não se espera que votem contra a vontade dos titulares, que saíram para serem ministros e devem obediência ao presidente da República. Apesar de ser um número aparentemente pouco expressivo (aproximadamente $10 \%$ da Casa), ele pode ser importante em votações conflituosas e decisivas. Isso ajuda a confirmar a ideia de que o Senado tem um papel mais "nacional" . e menos regional ou federativo - e a relação privilegiada que ele parece ter com o dirigente máximo da nação (NEIVA \& SOARES, 2010). Embora com maior intensidade, é curioso que tal relação já estivesse presente na época do Império: ao contrário dos deputados que perdiam suas vagas no Legislativo, os 
senadores nomeados pelo Imperador para o cargo de ministro ou conselheiro do Estado continuavam a ter assento na Casa, acumulando as duas funções (art. 29 da Constituição de 1824).

Não se pode fazer analogias entre os senadores do Império, os biônicos do regime militar e os suplentes do período democrático. O pouco que eles têm em comum é o fato de serem escolhidos a partir de preferências pessoais e não da vontade do eleitor. Os contextos também são muito diferentes; nesses quase duzentos anos de história, o país passou por muitas e intensas transformações, inclusive no seu sistema político: de Império para República; de unitário para federativo; de ditadura para democracia. Até uma experiência imperfeita e efêmera de semipresidencialismo foi tentada. Talvez a única característica institucional fundamental que se manteve constante foi o arranjo bicameral, com um Senado forte, composto por uma elite política que abrangeu quase todos os principais líderes da nossa história.

O que as diferentes formas de recrutamento experimentadas no Senado brasileiro mostram é a característica "camaleônica" das Câmaras Altas, que se adaptam facilmente a sistemas políticos e situações diversos (TSEBELIS \& MONEY, 1997). No caso dos suplentes, essa pode ter sido uma forma de ajudar a viabilizar o nosso presidencialismo de coalizão. Na Câmara dos Deputados, a literatura tem mostrado que os poderes do presidente e a organização centralizada foram elementos fundamentais para garantir a capacidade governativa. No Senado - uma casa mais independente, mais informal, menos hierarquizada e com grandes lideranças nacionais e regionais - a negociação pode não ser tão simples. Ainda que pequeno, o apoio de um grupo de legisladores que não dependem do clamor das urnas pode ser fundamental. No entanto, a nossa pretensão neste artigo não foi a de explicar o funcionamento da Casa, mas tão somente a de avaliar como senadores suplentes entram nessa discussão, que está só começando.

\section{Referências Bibliográficas}

AMORIM NETO, O. "Gabinetes presidenciais, ciclos eleitorais e disciplina legislativa no Brasil". Dados, v.43, n.3, 2000.

BOAVENTURA, H. e LIMA, P. “Senadores sem voto”. Jornal Correio Brasiliense, p.2a-2d, 08 fev. 2004.

Brasil. Constituição Politica do Imperio do Brazil. Presidência da República, 1823. Disponível em: <http://www.planalto.gov.br/ccivil_03/Constituicao/Constitui\%C3\%A7ao24.htm>. Acesso em: 24 maio 2011.

Brasil. Constituição dos Estados Unidos do Brasil. Presidência da República, 1891. Disponível em: <http://www.planalto.gov.br/ccivil_03/Constituicao/Constitui\%C3\%A7ao91.htm>. Acesso em: 24 maio 2011.

Brasil. Constituição dos Estados Unidos do Brasil. Presidência da República, 1946. Disponível em: <http://www.planalto.gov.br/ccivil_03/Constituicao/Constitui\%C3\%A7ao46.htm>. Acesso em: 24 maio 2011.

Brasil. Constituição da República Federativa do Brasil. Presidência da República, 1967. Disponível em: <http://www.planalto.gov.br/ccivil_03/Constituicao/Constitui\%C3\%A7ao67.htm>. Acesso em: 24 maio 2011.

Brasil. Decreto-Lei 1.543, de 15.04.77. Presidência da República, 1977. Disponível em: <http://www.planalto.gov.br/ccivil_03/Decreto-Lei/1965-1988/Del1543.htm>. Acesso em: 24 maio 2011.

Brasil. Constituição da República Federativa do Brasil de 1988. Presidência da República, 1988. Disponível em: <http://www.planalto.gov.br/ccivil_03/Constituicao/Constituicao.htm>. Acesso em: 24 maio 2011. 
NEIVA, P.; IZUMI, M. Os sem-voto do legislativo brasileiro: quem são os Senadores...

CHAIA, V.; \& TEIXEIRA, M. "Democracia e escândalos políticos". São Paulo em Perspectiva, v.15, n.4, 2001.

CHEIBUB, J.; FIGUEIREDO, A.; \& LIMONGI, F. Presidential agenda power and decision-making in presidential regimes: governors and political parties in the Brazilian Congress. In: AMERICAN POLITICAL SCIENCE ASSOCIATION, $29^{\circ}$ Encontro Anual, 2002, Boston, 29 ago. $\cdot 01$ set.

CONGRESSO EM FOCO. "Deputado custa pelo menos R\$ 99 mil e senador, R $\$ 120$ mil". Disponível em: <http://congressoemfoco.uol.com.br/noticia.asp?cod_canal=21\&cod_publicacao=33560>. Acesso em: 20 maio 2011.

COTTA, M., \& BEST, H. Democratic representation in Europe: diversity, change, and convergence. Oxford: Oxford University Press, USA, 2007.

D’ARAUJO, M. Governo Lula: Contornos sociais e políticos da elite do poder. Rio de Janeiro: CPDOC, 2007.

DAHL, R. Democracy and its Critics. New Haven: Yale University Press, 1989.

DI PALMA, G. To Craft Democracies: an essay on democratic transitions. Berkeley: University of California Press, 1990.

FERREIRA, J. Suplência senatorial: Uma análise de representatividade. Brasília, 2008.

FIGUEIREDO, A.; \& LIMONGI, F. "Congresso Nacional: organização, processo legislativo e produção legal”. Cadernos de Pesquisa CEBRAP, São Paulo, v.5, 1996.

Executivo e Legislativo na Nova Ordem Constititucional. Rio de Janeiro: Editora FGV, 1999.

IPU. Interparliamentary Union, 2011. Disponível em: <www.ipu.org>. Acesso em: 25 maio 2011.

LEMOS, L. B., MARCELINO, D., \& PEDERIVA, J. H. "Porque dinheiro importa: a dinâmica das contribuições eleitorais para o Congresso Nacional em 2002 e 2006". Opinião Pública, v.16, n.2, p.366.393, 2010.

LEMOS, L. B. S.; \& RANINCHESKI, S. "Carreras políticas en el Senado brasileño: Un estudio de las composiciones del Pleno y de la Comisión de Constitución, Justicia y Ciudadanía en la década de 90". Lateinamerika Analysen, v.4, p.3.30, 2003.

LIMONGI, F. "A democracia no Brasil: presidencialismo, coalizão partidária e processo decisório". Novos Estudos CEBRAP, n.76, p.17.41, 2006.

MANIN, B. "La democracia de los modernos. Los principios del gobierno representativo". Revista Sociedad - Facultad de Ciencias Sociales (UBA), n. 6, p. 1·20, 1995.

MIGUEL, L. F. "Capital político e carreira eleitoral: algumas variáveis na eleição para o Congresso brasileiro". Revista de Sociologia e Política, s/ v, n.20, p.115.134, 2003.

MORAES, E. "Reforma política no Brasil: Análise das reformas propostas pelo Senado (1998) e pela Câmara dos Deputados (2003)". [Dissertação (mestrado)] Ciência Política, Unb, 2006.

NEALE, T. "Filling US Senate vacancies: Perspectives and contemporary developments". Washington: Congressional Research Service, 2009.

NEIVA, P. "Os determinantes da existência e dos poderes das câmaras altas: federalismo ou presidencialismo?" Dados, v.49, n.2, p.269.299, 2006.

NEIVA, P. \& SOARES, M. Influência dos Partidos e Governadores sobre o Comportamento Legislativo dos Senadores Brasileiros. In: ABCP, 7o. Encontro, 2010, Recife.

O’DONNELL, G. “Teoria democrática e política comparada”. Dados, v.42, p.577.654, 1999.

OLIVEIRA, J. "Os institutos de controle da democracia brasileira ainda carentes de aperfeiçoamento". Revista de Informação Legislativa, v. 42, n.166, p. 205-220, 2005.

PEREIRA, C., \& MUELLER, B. "Comportamento estratégico em presidencialismo de coalizão: as relações entre executivo e legislativo na elaboração do orçamento brasileiro". Dados, v.45, n.2, p. 265·301, 2002.

PERISSINOTTO, R.; \& MIRÍADE, A. "Caminhos para o parlamento: candidatos e eleitos nas eleições para deputado federal em 2006." Dados - v. 52, n.2, p. 301-333, 2009. 
PESSANHA, C.; \& BACKES, A. Suplentes de parlamentares. In: AVRITZER, L. \& ANASTASIA, F. (eds.). Reforma política no Brasil. Belo Horizonte: Editora UFMG, 2007.

PRZEWORSKI, A.; STOKES, S. \& MANIN, B. Democracy, accountability and representation. Cambridge: Cambridge University Press, 1999.

RUDY, J. "O Suplente de Pedreiro". Correio Braziliense, p. 2, 2004.

SAMUELS, D.; \& SNYDER, R. "The value of a vote: malapportionment in comparative perspective". British Journal of Political Science, v.31, n.4, p.651.671, 2001.

SANTOS, A. M.; \& SERNA, M. "Por que carreiras políticas na esquerda e na direita não são iguais? Recrutamento legislativo em Brasil, Chile e Uruguai”. Revista Brasileira de Ciências Sociais, v.22, n.64, p. 93-113, 2007.

SANTOS, F. Deputados federais e instituições legislativas no Brasil: 1946.99. In: SANTOS, F. BOSCHI, R. \& DINIZ, E. (Eds.). Elites políticas e econômicas no Brasil contemporâneo. São Paulo: Konrad Adenauer Stiftung, 2000.

“Partidos e comissões no presidencialismo de coalizão." Dados, v.45, n.2, p.237.264, 2002.

SCHUMPETER, J. Capitalismo, socialismo e democracia. Rio de Janeiro: Zahar, 1984.

STEPAN, A. "Para uma nova análise comparativa do federalismo e da democracia: federações que restringem ou ampliam o poder do demos". Dados, v.42, n.2, 1999. 169,2000

"Brazil's decentralized federalism: Bringing government closer to the citizens?" Daedalus, v. 129, n.2, p. 145.

TSEBELIS, G., \& MONEY, J. Bicameralism: Political economy of institutions and decisions. Cambridge: Cambridge University Press, 1997

URIARTE, E. "El análisis de las elites políticas en las democracias". Revista de Estudios Políticos, n.97, p. 249.275, 1997.

WEBER, M. Ciência e política: duas vocações. São Paulo: Cultrix, 1999.

WEFFORT, F. "Qual reforma política?" Estudos Avançados, v. 23, n.67, p. 37.45, 2009. 
NEIVA, P.; IZUMI, M. Os sem-voto do legislativo brasileiro: quem são os Senadores...

Apêndice

Forma de seleção dos suplentes nos países onde os titulares são escolhidos diretamente

\begin{tabular}{|c|c|}
\hline Argélia & Nova eleição \\
\hline Butão & Nova eleição \\
\hline Filipinas & Nova eleição \\
\hline Haiti & Nova eleição \\
\hline Libéria & Nova eleição \\
\hline Nigéria & Nova eleição \\
\hline Palau & Nova eleição \\
\hline Suíça & Nova eleição \\
\hline Polônia & Nova eleição \\
\hline Espanha & Nova eleição \\
\hline Tailândia & Nova eleição \\
\hline Zimbábue & Nova eleição \\
\hline Argentina & Eleito na mesma época que o titular \\
\hline Paraguai & Eleito na mesma época que o titular \\
\hline Uruguai & Eleito na mesma época que o titular \\
\hline Japão & Eleito diretamente no próximo pleito \\
\hline Itália & Segundo da lista eleitoral \\
\hline Colômbia & Segundo da lista eleitoral \\
\hline Chile & Partido escolhe \\
\hline Austrália & Assembleia estadual escolhe \\
\hline Estados Unidos & Governador escolhe 20 \\
\hline República Dominicana & $\begin{array}{l}\text { Escolhido pelo Senado a partir de lista tríplice sugerida } \\
\text { pelo partido }\end{array}$ \\
\hline República Tcheca & Encerra o mandato \\
\hline Bolívia & Lei definirá a forma \\
\hline México & Escolhido pelo titular antes da eleição \\
\hline Brasil & Escolhido pelo titular antes da eleição \\
\hline
\end{tabular}

Fonte: elaboração própria a partir das respectivas constituições

Pedro Neiva·prneiva@gmail.com

Mauricio Izumi·mauricioizumi@hotmail.com

Recebido para publicação em dezembro de 2010.

Aprovado para publicação em agosto de 2011.

\footnotetext{
${ }^{20}$ Há variações entre os estados: em Massachusetts, Oregon e Wisconsin, os substitutos dos senadores são escolhidos em eleições especiais, e não pelo governador; no Arizona, o senador indicado deve ser do mesmo partido do "incumbente"; no Havaí, em Utah e em Wyoming, o governador deve escolher o senador temporário a partir de nomes submetidos pelo partido do titular; em Massachusetts, Oregon e Wisconsin, devem ser realizadas novas eleições para preenchimento das vagas (NEALE, 2009).
} 